\title{
Can we estimate a monetary value of scientific publications ${ }^{1}$ ?
}

\author{
Sandra ROUSSEAU (KU Leuven) - CORRESPONDING AUTHOR \\ Faculty of Economics and Business, CEDON, KU Leuven \\ Warmoesberg 26, B-1000 Brussel, Belgium \\ E-mail: Sandra.Rousseau@kuleuven.be, +32 26098275
}

\author{
Giuseppe CATALANO (Sapienza University of Rome) \\ Via Ariosto, 25, 00185 - Rome - Italy \\ Email: giuseppe.catalano@uniroma1.it
}

\author{
Cinzia DARAIO (Sapienza University of Rome) \\ Via Ariosto, 25, 00185 - Rome - Italy \\ Email: cinzia.daraio@uniroma1.it
}

Published as: Rousseau, S., Catalano, G. \& C. Daraio. (2021). Can we estimate a monetary value of scientific publications? Research Policy, 50(1) (doi: 10.1016/j.respol.2020.104116)

1 The financial support of the Sapienza University of Rome (through H2020 Sapienza Awards, N. PH11715C8239C105) is gratefully acknowledged. We thank Antonella Cammisa, Guido Pepermans, Andrea Riccio, Eline Poelmans and Ronald Rousseau for their great support to the development and the implementation of the Survey, Giuseppe Foti for providing the data of the distribution of Sapienza's scholars and of their salary, and Teodoro Valente, the Deputy Rector for Research, Innovation and Technology Transfer of Sapienza University for his comments on the paper. 


\begin{abstract}
In this paper, we analyze the compelling issue of monetary valuation of a scientific publication. While many academic scholars tend to overlook the topic, as being either too difficult or even meaningless, policymakers begin to use very rough tools for evaluating publications, which have many limitations, as we will discuss in this work. The main objective of this work is to address this open problem by stimulating further discussion on the topic and future research developments. We provide an overview of different methods to value scientific publications. We discuss their main hypotheses, pros and cons by means of an illustration based on Sapienza University of Rome. Although we begin to address the issue of monetary valuation of scientific publications, presenting a range of available methods and listing the limits and benefits of each, further methodological and empirical research is still needed to comply with policy and stakeholders' needs which we expect will increase in the near future.
\end{abstract}

Keywords: impact assessment; economics of science; non-market valuation 


\section{Introduction}

Cost-benefit analysis (in short: CBA) has been used as a tool for public policy decision making for almost a century in a variety of policy settings (De Rus, 2010; Nyborg, 2012). While CBA has been used for the evaluation of research and innovation projects in the past (e.g., Wise, 1975; Geuna \& Martin, 2003), recently this approach has gained momentum and is used actively in impact assessment studies and policy development (e.g., DG Regio, 2014). This fits within the growing awareness of researchers and policymakers to expand the knowledge base on all impacts of research and research policy. This trend is illustrated by the review of the role of metrics in research assessment and management (Wilsdon et al., 2015) and by the study of Hill (2016) which states that: "the assessment of societal impact needs to become a more central aspect of research evaluation".

A larger number of past studies have focused on the economic benefits of privately and publicly funded research and have studied the link between research and economic growth and new business opportunities (Salter \& Martin, 2001; Martin \& Tang, 2007; Castelnovo et al., 2018). Other studies have examined the societal impacts of research in a broader sense, going beyond economic impacts (Bornmann, 2013; Bornmann \& Marx, 2014; Hill, 2016; Greenhalgh et al., 2016). The evaluation of the impact of science can rely on different approaches. Bozeman and Sarewitz (2011), for instance, consider a non-economic model for the social value of science and innovation policy. Molas-Gallart and Tang (2011) and Spaapen and Van Drooge (2011) based their analysis on information about knowledge exchange interactions such as joint research papers. As another recent example, GarcíaRomero et al. (2017) investigated the impact of health research on length of stay in Spanish public hospitals. Investments in research and knowledge development generate benefits for researchers, young professionals and students, but also for businesses, the target population and the general public (DG Regio, 2014). While some of these benefits are easy to quantify and value in monetary terms, others are much more challenging to value. Specifically, we focus on the monetary value of scientific publications and how these values can be included when implementing a cost-benefit analysis in a research setting. In order to assess the main strengths and weaknesses of several available valuation methods, we use the Italian generalist university Sapienza as a case to illustrate different approaches.

Scientific publications are one of the many outcomes of research activity besides patents, doctoral research, and so on. Research activities are carried out in the context of new knowledge production processes (Gibbons et al., 1994; Nowotny et al., 2001, 2003). The definition of 'what a publication is' represents a challenge, it is difficult and articulated. For instance, in Sapientia, the Ontology of Multidimensional Research Assessment (Daraio et al., 2016), a publication aims at reporting empirical 
or theoretical work and describes the results in some knowledge field. Publications are described in the Module Publishing, which concerns the activity that allows people to know the results of research. The output of a publishing activity is a publication, which is a way to represent a content through some media. There are three kinds of content in Sapientia: paper-like content (a content structured as a paper); book-like content (a content structured as a monograph or edited chapter) and patent-like content (a content structured as a patent application). It has to be noted that a publication of a research work is not considered as output of that work (the output of the work is the content of the publication, see Lenzerini and Daraio, 2019). Thus, we consider the value of publications as separate from the value of scientific results, and in this study we specifically focus on the authors' perspective. Understanding authors' attitudes towards publications and how they value different publication types is important for research institutions and policymakers to help in developing effective and relevant research programs. This focus implies that this study mainly captures use values of publications, which refer to the benefits an individual or organization can acquire through having direct access to a particular publication. These benefits can include new insights after reading or writing a publication, but also capacity-building and reputational effects. Publications are only one way to disseminate research findings (or contents). Alternatives are patents, presentations, informal collaborations, or researchers could decide not to share the findings at all, because the results are not interesting, not new or because the researcher does not have the time to write everything down.

In this paper, we focus on scientific publications, namely articles which are one way of communicating the paper-like content that was mentioned above. This type of content can be communicated through a variety of outlets such as national and international journals, chapters in books or conference proceedings. While publications are seen as an important output of scientific activities, it is not straightforward to assess their value. A quantitative evaluation of scientific publications is affected by many challenges, including but not limited to: complexity and articulation of the research activity with respect to the problem to solve; uncertain and unpredictable time lag between the research activity and the realization of the scientific publication, accounting for the tacit knowledge embedded in human minds and codified knowledge embedded in documentary sources as well as on their complementarities and attribution of the publication to the research it refers.

We claim that it is important to assess different methods to provide a monetary value of publications in a systematic way because it is important to be explicit about the conditions and assumptions underlying the different methods. Moreover, one cannot simply ignore these issues (i.e. CBA, monetary valuation of research and research outputs) because doing nothing is also a choice and 
has implications: either the publications are ignored and implicitly valued at zero, or the policymakers use the few available studies without taking the conditions where these results can be used into account and thus with limited understanding of the implications of that choice. Tuckman and Leahey (1975) were the first to calculate the worth of an article by exploiting wage differences for 973 full-time male faculty employed at US universities in 1972-1973. The results of their hedonic wage estimation suggest that the returns from the publication of the first article are considerable, ranging from 12340 USD for an assistant professor, to 10256 USD for an associate professor, to 6958 USD for a full professor, based on a $5 \%$ discount rate. Diamond (1985) used a similar method to estimate the impact of a citation on earnings and found that the marginal value of a first citation varies between 50 and 1300 USD.

In the remainder of this paper, we describe several methods that are available to estimate the value of a publication and illustrate how they can be used for the case of Sapienza University. The paper is organized as follows. First, we provide some general background on the concept of value and how it can be measured. Next, the framework of the application to Sapienza University of Rome and the data collection process are described. We apply a market-based method and study market prices for some selected publications. A second approach to value publications is the marginal production cost method which is illustrated for publications from researchers affiliated with Sapienza University of Rome. The third and last approach is based on a survey-based technique called discrete choice experiments. Finally, we compare the three different approaches to value publications and conclude.

\section{Methods and valuation approaches}

\subsection{Some general background}

Before we can start to value, we must briefly consider what value is. Economic value can typically be divided into two main categories: use values and non-use values. Use values refer to the benefits an individual or organization can acquire through having access to a particular good or service. These benefits can include new insights after reading or writing a publication, but also capacity-building (e.g. the ability to work across the academic/non-academic boundary, expanded expertise and skills in handling toolsets, such as visualization tools). Non-use values refer to benefits associated with the existence of a publication without personally having access to it. These values include the feeling that it is important to have publications to advance science and to keep evolving as a society (existence value). Individuals may also feel that is important to have publications for the benefit of the next generation (bequest value) or for other totally unrelated researchers of the current generation (altruistic value). While use values of publications will typically be acquired by researchers and academics, non- 
use values can be acquired by all individuals in a society and as such scientific knowledge can be seen as a public good. Since values are not only attained in the present but can also be expected in the future, the (quasi) option value can be defined to reflect these future use and non-use values. Generally, and also in this specific case where we focus on the authors' perspective, use values are easier to estimate than non-use values. The methods used in the illustration will typically estimate use values, with the exception of the discrete choice experiment that can also capture part of the non-use value.

A large majority of past studies regarding the value of research have focused on use values (see, e.g., Martin \& Tang, 2007; Salter \& Martin, 2001; Bornmann, 2013). This is nicely illustrated by the following quote: 'Society can reap the benefits of successful research studies only if the results are converted into marketable and consumable products (e.g., medicaments, diagnostic tools, machines, and devices) or services.' (Bornmann, 2013, p.217). Furthermore, the idea that a publication has more value when it is cited more frequently (Waltman et al., 2013) is also focusing on use values of research.

However, non-use values of research are explicitly mentioned in the cost-benefit framework presented by Florio et al. (2016b) and have been estimated in Florio et al. (2016a) for the Large Hadron Collider (LHC) at CERN. The non-use value of the LHC was defined as 'its value for people who currently do not use its services, but who derive utility by just knowing that new science is created' (Florio et al., 2016a, p.39; Catalano et al., 2016). The estimation of an individual's willingness-to-pay was estimated though the survey-based contingent valuation method and resulted in an estimated nonuse value of 3.2 billion euro for the investment at CERN (Florio et al., 2016a).

In order to measure these values and preferences, the literature typically distinguishes three broad categories of economic valuation methods as presented in Table 1 (Pearce et al., 2006; De Rus, 2010). The first group of methods is based on actual markets and prices. The second way of gaining insight into individuals' preferences is based on their behavior in related markets such as selecting a job, buying a house or visiting a research facility and these methods are called revealed preference methods. The third way of estimating preferences is based on surveys in which individuals state their preferences directly or indirectly and these methods are called stated preference methods. While each approach can be used to measure use values, only the last approach, based on surveys, can be used to measure non-use values. These valuation methods are frequently used to assess the value of non-market goods such as biodiversity improvements (e.g. Rousseau \& Tejerizo Fuertes, 2020) or health impacts (e.g. Mangham et al., 2009). 
Table 1: Overview of valuation methods

\begin{tabular}{|c|c|c|}
\hline Based on & Available methods & Potential applications to publications \\
\hline \multirow[t]{3}{*}{$\begin{array}{l}\text { Existing markets } \\
\text { (use values) }\end{array}$} & Market prices & 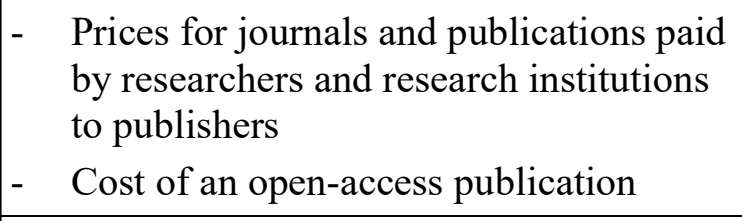 \\
\hline & $\begin{array}{l}\text { Cost-based methods } \\
(\text { replacement costs...) }\end{array}$ & 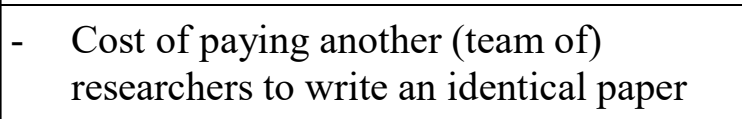 \\
\hline & Production cost methods & - $\quad$ Marginal production costs approach \\
\hline $\begin{array}{l}\text { Related markets } \\
\text { (revealed preferences) } \\
\text { (use values) }\end{array}$ & $\begin{array}{l}\text { Travel cost method } \\
\text { Hedonic price method } \\
\text { (prices, wages, ...) }\end{array}$ & 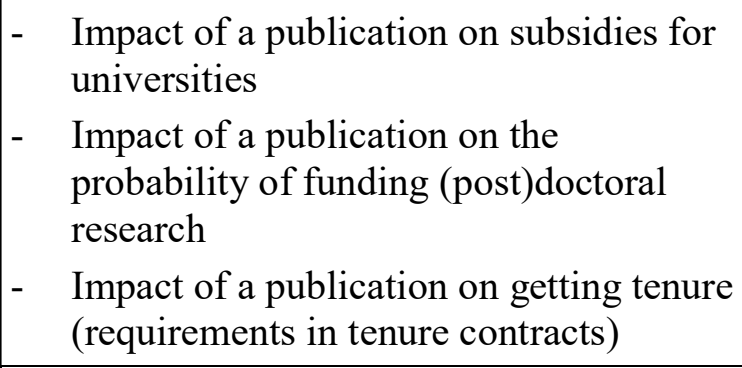 \\
\hline $\begin{array}{l}\text { Hypothetical markets } \\
\text { (stated preferences) } \\
\text { (use and non-use values) }\end{array}$ & \begin{tabular}{|l|} 
Contingent valuation \\
Discrete choice experiments
\end{tabular} & $\begin{array}{l}\text { Survey measuring support for a specific } \\
\text { research project } \\
-\quad \begin{array}{l}\text { Survey measuring the relative } \\
\text { characteristics of publications }\end{array}\end{array}$ \\
\hline
\end{tabular}

Next, we investigate how these different methods can be used to approximate several aspects of the use value of a publication. Based on the first approach of existing markets, we examine market prices for journals and journal articles and we discuss the production cost approach used by Florio et al. (2016b) and Battistoni et al. (2016). The application of the cost-based method based on replacement costs is difficult to implement in practice as specific expertise and knowledge, which are typically unique to individual researchers or researcher teams, are needed to write a particular paper. Based on the second approach of related markets, the travel cost method - which relies on people's willingness to make certain trips or visits to derive the implicit value of these activities - cannot directly be applied to estimate the value of a publication. The hedonic price method can be used in this context by looking at the impact of subsidies on university funding or by investigating the impact of an additional publication on a researcher's career and then specifically on expected wages (e.g. Tuckman \& Leahey, 1975; Diamond, 1985). Based on the third approach of hypothetical markets, we perform a discrete choice experiment but do not apply the contingent valuation method. The latter method can be used to estimate use and non-use values of research infrastructure (e.g. Florio et al. (2016a) used this method 
to assess the value of the LHC at CERN), but its focus on one large project or policy measure makes this method less suitable to derive the value of a scientific publication.

The four methods that show the highest potential in the current context are discussed in more detail below and illustrated with survey results for academics affiliated to Sapienza University of Rome. This case study, as all case studies, is not meant to be exhaustive but is a tool to start with and discuss the main strengths and weaknesses of these approaches and, most importantly, the possible use of such estimated values in impact assessment of research and research institutions.

\subsection{Existing markets: Prices for publications}

In well-functioning markets, prices provide accurate information on value and reflect stakeholders' preferences. Conditions for the well-functioning of markets include perfect information, a large group of buyers and sellers (no market power), the absence of externalities as well as well-defined property rights. Thus, while market prices can, in theory, approximate the true value of good quite closely, this is unlikely to happen in real markets. Real markets often exhibit market failures (i.e. one or more of the above-mentioned conditions does not hold) and can also be influenced by regulatory interventions such as taxes and subsidies. In our illustration based on the case study for Sapienza University, we focus on the price of open-access publications. First, we generate a list of the 8432 publications of authors affiliated with Sapienza University of Rome published in 2018 and indexed in the Web of Science $^{2}$. Next, we randomly selected 50 of these publications (full list in Supplementary material A) and searched for the cost of publishing an open access article in the source journal ${ }^{3}$.

\subsection{Existing markets: The marginal production cost approach}

Inspired by Florio et al. (2016b) and DG Regio (2014), we now have a closer look at the marginal production cost approach. This approach was also used in Battistoni et al. (2016) to value the knowledge outputs from the National Hadrontherapy Centre for Cancer Treatment (CNAO) located in Pavia (Italy).

When scientists and researchers spend time working on a publication, they are foregoing the opportunity of working on an alternative project or even in an alternative sector. If this opportunity cost is assumed to equal the average scientist's hourly compensation, Florio et al. (2016b) claim that a reasonable proxy of the value of scientific output is its marginal scientific cost. According to economic theory, the marginal production cost represents the incremental costs incurred when producing an additional unit of a good or service (here, a publication). In practice, it is often calculated

\footnotetext{
${ }^{2}$ We used the following query: OO=Sapienza* AND PY=2018.

${ }^{3}$ If the random selection resulted in a conference proceeding or book, the next journal article in the list was used.
} 
by taking the total change in costs of producing more goods and dividing that by the change in the quantity of goods produced. The usual variable costs included in the calculation are labor and materials, plus the estimated increases in fixed costs (if any), such as administration and overhead. In the context of academic publications, Florio et al. (2016b) define this marginal scientific cost as the time spent by scientists to conduct research and produce knowledge outputs valued at appropriate shadow wages.

Florio et al. (2016b) use the marginal production cost approach to estimate the unit production cost (UPC) per knowledge output as the ratio of the weighted gross salary of the author - which depends on his/her function - over the number of scientific outputs produced per year:

$$
\begin{gathered}
U P C=\left(\sum_{\text {function }} \text { gross annual salary } x \text { share of time spend on research }\right) \\
/(\text { number of publications })
\end{gathered}
$$

As an example of this approach, if a researcher spends $50 \%$ of its time on research, has a gross annual wage of 100000 euro and published two articles per year on average, then the value of a publication would be estimated at 25000 euro.

In our case study based on Sapienza University, we use an online survey to collect information on the estimated share of time each researcher dedicate to research, their function and their publications. Thus, we use self-reported data in this illustration. Information on the average gross annual salary per function was obtained from the human resources department of Sapienza.

\subsection{Related markets: hedonic price method}

The number of publications written by a researcher or institution can also have an impact on other markets or financial decisions such as the academic job market or the funding of universities. The hedonic price method exploits this connection to derive an implicit value of a scientific publication. As mentioned in the introduction, the studies of Tuckman and Leahey (1975) and Diamond (1985) provide an example of an application based on a related market, namely researchers' wages.

As another example, we consider an application based on the impact of publications on university funding. In 2014, the Italian Ministry of Higher Education introduced a performance-based funding system, which was based on research and teaching performance indicators (Aversano et al., 2018). The system is formula-based with an annually increasing weight of performance-based indicators. In 2018 , the fund is allocated for $20 \%$ on a performance basis and for $80 \%$ on an expenditure basis based on a standard cost per regular student. The $20 \%$ performance-based share of funding is allocated as follows (Aversano et al., 2018): 70\% based on university performance in the national research assessment 
framework "Valutazione della Qualità della Ricerca" (VQR); 10\% based on the quality of recruitment (i.e., the VQR research performance of newly hired faculty); and $20 \%$ based on the internationalization of teaching activities (i.e., number of Erasmus students and credits from courses attended overseas). Publications, and especially publications indexed in the Web of Science or Scopus, play an important role in the VQR. As more, and higher quality, publications lead to a more better assessment of a university's performance and this lead to a higher share of funding, this relationship can be used to derive a monetary value of a publication. Unfortunately, these data are not available for multiple Italian university of a sufficiently large time period and we are thus not able to estimate the value of a publication through this approach.

\subsection{Hypothetical markets: Discrete choice experiment}

A discrete choice experiment (DCE) is a quantitative technique used for eliciting individual preferences developed by Louviere and Hensher (1982) and Louviere and Woodworth (1983). It is especially suited to deal with multidimensional choices and is based on random utility theory (AmayaAmaya et al., 2008). This technique has already been used to investigate the selection of a journal where a researcher would submit his/her paper to (Rousseau \& Rousseau, 2012; Poelmans \& Rousseau, 2015).

In the current DCE, respondents are offered eight choice sets and each choice set $\mathrm{C}$ comprises four options: alternative $\mathrm{A}$, alternative $\mathrm{B}$, alternative $\mathrm{C}$ and the opt-out option. Choosing one alternative over the others implies that the utility of the chosen alternative exceeds the utility associated with the other alternatives. Thus, the probability of a respondent choosing scenario $i$ from a particular choice set $\mathrm{C}$ can be expressed as:

$$
\begin{aligned}
\operatorname{Pr}[i \mid C] & =\operatorname{Pr}\left[U_{i}>U_{j}, \forall j \neq i \in C\right] \\
& =\operatorname{Pr}\left[A S C_{i}+\beta X_{i}^{\prime}+\beta_{M} M_{i}+\varepsilon_{i}>A S C_{j}+\beta X_{j}^{\prime}+\beta_{M} M_{j}+\varepsilon_{j}, \forall j \neq i \in C\right]
\end{aligned}
$$

Where $U_{i}$ represents the utility derived by an individual of choosing alternative i out choice set C, where $X_{i}^{\prime}$ represents a $\mathrm{K}$-dimensional vector of attribute levels for alternative $\mathrm{i}$, where $\beta$ is a $\mathrm{K}$ dimensional vector of coefficients capturing generic marginal (dis)utilities of attributes, where $\mathrm{M}$ represents the monetary attribute, and where $\mathrm{ASC}_{\mathrm{i}}$ - alternative specific constant - captures the mean effect of unobserved factors for each of the alternatives.

Under the assumption that the random terms are independently and identically distributed following a type I extreme value distribution (i.e. a Gumbel distribution), the choice probabilities have a convenient closed-form solution, the so-called conditional logit model. The marginal willingness to 
pay (WTP) for a particular change in one specific attribute - the marginal rate of substitution - can be estimated as a ratio of coefficients:

$$
W T P_{\text {attribute }}=-\frac{\partial U / \partial X_{i}}{\partial U / \partial M}=-\frac{\beta_{\text {attribute }}}{\beta_{M}}
$$

For more information on the mathematical and statistical details of this method, we refer the reader to Alberini et al. (2007) and Amaya-Amaya et al. (2008).

Specifically, we asked each respondent to make eight choices between two types of publications, one funding opportunity or none of these three. Figure 1 illustrates one such choice card. We describe each publication type by the following characteristics (attributes): the type of outlet, its language, its standing with peers, the presence of co-authors and their disciplinary focus, and the time needed to write and revise the publication. Table 2 provides an overview of the attributes and their levels. The funding opportunity presented a budget of $500,1500,2500,3500$ to 5000 euro that could be used for research-related expenses and could be acquired with two weeks of work. If the two publications options as well as the funding opportunity did not appeal to the respondent, (s)he could select the optout option to indicate this.

Table 2: Attributes and attribute levels

\begin{tabular}{|l|l|}
\hline Attributes & Attribute levels \\
\hline Outlet & $\begin{array}{l}\text { Non-indexed national journal (reference) } \\
\text { Non-indexed international journal } \\
\text { Indexed (WoS, Scopus) journal } \\
\text { Chapter in national book } \\
\text { Chapter in international book } \\
\text { Contribution published in Conference proceedings }\end{array}$ \\
\hline Language & $\begin{array}{l}\text { Italian (reference) } \\
\text { English }\end{array}$ \\
\hline Standing/status of publication & $\begin{array}{l}\text { Low (reference) } \\
\text { Average } \\
\text { High }\end{array}$ \\
\hline Co-authors & $\begin{array}{l}\text { No co-authors }- \text { single author } \\
\text { Only local co-author(s) (reference) } \\
\text { At least one international co-author }\end{array}$ \\
\hline Dime needed to write and revise the publication & $\begin{array}{l}\text { All authors same discipline (reference) } \\
\text { At least one author from another discipline }\end{array}$ \\
\hline
\end{tabular}


19a7. Which of the following three options do you prefer?

(Funding can be used for anything related to research: conferences, software, books, wages...)

(An indexed journal is assumed to be indexed in both WoS and Scopus)

\begin{tabular}{|l|c|c|c|}
\hline & Publication A & Publication B & $\begin{array}{c}\text { Additional } \\
\text { funding for } \\
\text { research }\end{array}$ \\
\hline Type of outlet & $\begin{array}{c}\text { Article in indexed } \\
\text { journal }\end{array}$ & Article in non-indexed national journal & $/$ \\
\hline $\begin{array}{l}\text { Language of } \\
\text { publication }\end{array}$ & Italian & English & $/$ \\
\hline $\begin{array}{l}\text { Standing among } \\
\text { peers }\end{array}$ & High & Low & $/$ \\
\hline Co-authors & Single author & $\begin{array}{c}\text { At least one international co-author } \\
\text { discipline }\end{array}$ & $/$ \\
\hline $\begin{array}{l}\text { Personal time } \\
\text { invested in writing } \\
\text { and revising (FTE, } \\
\text { not waiting time) }\end{array}$ & 2 months & 3 months & 2 weeks \\
\hline \begin{tabular}{l} 
Budget \\
\hline
\end{tabular} & 0 euro & 0 euro & 500 euro \\
\hline
\end{tabular}

Publication A

Publication B

Additional funding

None of the three options

Figure 1: Example of a choice card

Based on these attributes and their levels, $6 \times 2 \times 3 \times 3 \times 2=216$ different publications can be constructed. Since respondents cannot rank all these alternatives, we selected a restricted set of choice cards to present to respondents that allow us to derive the most information from respondents' choices. Specifically, we created a d-efficient design based on fixed priors using Ngene leading to a choice experiment consisting of three blocks with each eight choice cards (see Supplementary material B). Respondents were randomly assigned to one of these three blocks.

Data obtained from a choice experiment are often estimated by conditional logit (CL) models. However, the CL model suffers from the independence of irrelevant alternatives (IIA). The CL model also assumes preference homogeneity across respondents, which implies that only one fixed vector of parameters is estimated for the choice attributes, and hence all respondents are assumed to have the same preference for the attributes (Hensher et al. 1999; Train, 2003). Conditional logit models can tackle heterogeneity by including socio-economic variables as interactions with attributes and alternative-specific constants, or by estimating different models for different subsets of data. An alternative approach that relaxes the IIA assumption and allows for heterogeneous preferences is to 
estimate a latent class (LC) model (Boxall \& Adamowics, 2002). Latent class methods aim to distinguish consumer segments based on discrete observed measures such as reported attitudes. A LC model estimates consumers choices jointly with class membership based on the assumption that utility functions are different between classes, but identical within classes. We estimate both a standard conditional logit model and a latent class model to analyze the data.

\section{Survey design and data collection}

Sapienza University of Rome is the largest generalist European university by enrollments and one of the oldest in history, founded in 1303. The University is one of the most prestigious Italian universities commonly ranking first in national rankings and in Southern Europe. Sapienza University of Rome was founded in 1303 with the Papal bull: In Supremae Praeminentia Dignitatis, issued on 20 April 1303 by Pope Boniface VIII. In the 1650s the university became known as Sapienza, meaning wisdom, a title it retains. Sapienza University, with its over 700 years of history, has 112,557 students, 3411 academics, and 2306 employees, technicians and librarians, in addition to 1812 administrative staff in university hospitals in $2018^{4}$.

To illustrate the methods discussed above, an online survey was developed in Qualtrics to gather data on the publication preferences of professors affiliated with Sapienza University of Rome. The survey included questions in English on socio-demographic characteristics of the respondents, function and research discipline as well as past publication behavior, attitudes towards and knowledge of bibliometric indicators and a DCE designed to learn about publication preferences.

After several tests of the formulation of the survey questions, a call to participate was launched on November 22, 2018 through email. We contacted all faculty members from Sapienza (N=3306) through a general mailing list. No reminders were sent. Data collection was closed on January 31, 2019.

Overall, 502 respondents started the survey of which 43 stopped after reading the introduction, another 33 stopped after filling their field of expertise ( $7^{\text {th }}$ question) and another 94 stopped when they were asked to describe their publications in the past three years ( $11^{\text {th }}$ question). After some additional limited drop-out, we ended with 313 useful, though not fully complete, responses. Thus, the response rate is low: $502 / 3306=15 \%$, or based on useful data, $313 / 3306=9.5 \%$. Such a low response rate is not unusual for online surveys (Fan \& Yan, 2010) and may be further affected by our choice not to

\footnotetext{
${ }^{4}$ https://www.uniroma1.it/sites/default/files/field file allegati/retro_2018 mod5bis_ridotta-abbondanze.pdf
} 
send reminders and to use English as a working language. We use the sample of 313 useful responses in the remainder of the text. As the main aim of the case study was to illustrate several valuation methods, the lack of external validity is not crucial.

The sample consisted of $64 \%$ male and $36 \%$ female respondents. All respondents, with the exception of three, had the Italian nationality. The average age of the respondents was 52.7 with a minimum of 29 and a maximum of 76 . Respondents are affiliated with eleven different faculties plus the School of Aerospace Engineering, with the largest proportion (19\%) from the Faculty of mathematics, physics and natural sciences, followed by the Faculty of arts and philosophy (12\%) and the Faculty of information engineering, computer science and statistics (12\%) (Table 3). Table 3 reports in bold the percentages of respondents (“\% resp." second column of Table 3) of the faculties that are higher than the respective percentage in the population of Sapienza's scholars ("\% N." sixth column of Table 3). The respondents had different functions, but the largest group (39\%) is associate professor, followed closely by the group (35\%) of assistant professors (see Table 4 that reports also the relative distribution in the Sapienza's population). Based on chi-squared goodness-of-fit tests, we reject the null-hypothesis that the distribution of our sample over faculties is equal to the population distribution $\left(\mathrm{chi}^{2}=46.11, \mathrm{p}=0.0000\right)$ and do not reject the null-hypothesis for the distribution of functions $\left(\mathrm{chi}^{2}=13.77, \mathrm{p}=0.0554\right)$, and the distribution of gender in our sample $\left(\mathrm{chi}^{2}=1.86, \mathrm{p}=0.3952\right)$.

Table 3: Description of the dataset. For the 11 faculties of Sapienza plus the School of Aerospace Engineering, grouped in 5 macro-area's groups, we report the number of respondents (N. resp.) and \% of respondents (\% of resp). The last two columns show the total number of academics in place at the 31 December 2018 (“Total N. (2018)”) and their \% (“\% N.”) distributed by faculty.

\begin{tabular}{|l|l|c|c|r|r|}
\hline Faculty & Group & $\begin{array}{l}\text { N. of } \\
\text { resp. }\end{array}$ & $\begin{array}{c}\text { \% of } \\
\text { resp. }\end{array}$ & $\begin{array}{r}\text { Total N. } \\
\mathbf{( 2 0 1 8 )}\end{array}$ & \% N. \\
\hline $\begin{array}{l}\text { Scienze matematiche, fisiche e naturali } \\
\text { (Mathematics, Physics and Natural Sciences) }\end{array}$ & Exact sciences & 59 & $\mathbf{1 8 . 8 5}$ & 417 & 12.61 \\
\hline $\begin{array}{l}\text { Lettere e filosofia } \\
\text { (Arts and Humanities) }\end{array}$ & Humanities & 38 & $\mathbf{1 2 . 1 4}$ & 376 & 11.37 \\
\hline $\begin{array}{l}\text { Architettura } \\
\text { (Architecture) }\end{array}$ & Engineering \& & 9 & 2.88 & 168 & 5.08 \\
\hline $\begin{array}{l}\text { Ingegneria civile e industrial } \\
\text { (Civil and Industrial Engineering) }\end{array}$ & Technology & 37 & $\mathbf{1 1 . 8 2}$ & 289 & 8.74 \\
\hline
\end{tabular}




\begin{tabular}{|c|c|c|c|c|c|}
\hline $\begin{array}{l}\text { Ingegneria dell'informazione, informatica e } \\
\text { statistica (Information Engineering, Informatics } \\
\text { and Statistics) }\end{array}$ & & 38 & 12.14 & 222 & 6.72 \\
\hline $\begin{array}{l}\text { Scuola di Ingegneria aerospaziale (School of } \\
\text { Aerospace Engineering) }\end{array}$ & & 2 & 0.64 & 10 & 0.30 \\
\hline $\begin{array}{l}\text { Farmacia e medicina } \\
\text { (Pharmacy and Medicine) }\end{array}$ & \multirow{3}{*}{ Medical sciences } & 36 & 11.50 & 461 & 13.94 \\
\hline $\begin{array}{l}\text { Medicina e odontoiatria (Medicine and } \\
\text { Dentistry) }\end{array}$ & & 32 & 10.22 & 584 & 17.66 \\
\hline $\begin{array}{l}\text { Medicina e psicologia (Medicine and } \\
\text { Psychology }\end{array}$ & & 29 & 9.27 & 331 & 10.01 \\
\hline Economia (Economics) & \multirow{3}{*}{ Social sciences } & 11 & 3.51 & 179 & 5.41 \\
\hline Giurisprudenza (Law) & & 4 & 1.28 & 86 & 2.60 \\
\hline $\begin{array}{l}\text { Scienze politiche sociologia comunicazione } \\
\text { (Political Science, Sociology and } \\
\text { Communication Science) }\end{array}$ & & 18 & 5.75 & 183 & 5.54 \\
\hline
\end{tabular}

Table 4: Description of the dataset. Distribution of respondents by function and gender compared with the distribution of the population of Sapienza university at 31 December 2018 (“Total N. (2018)" and “\% N.").

\begin{tabular}{|l|c|c|c|c|}
\hline Function & N. of resp. & \% of resp. & $\begin{array}{l}\text { Total N. } \\
\mathbf{( 2 0 1 8 )}\end{array}$ & \% N. \\
\hline Professore ordinario (Full professor) & 60 & 19.17 & 674 & 20.39 \\
\hline Professore associato (Associate Professor) & 121 & 38.66 & 1161 & 35.12 \\
\hline Ricercatore (full-time assistant professor) & 69 & 22.04 & 1102 & 33.33 \\
\hline Professori incaricati (contract professor) & 8 & 2.56 & NA & NA \\
\hline $\begin{array}{l}\text { Ricercatori a tempo determinato L. 230/05 (temporary } \\
\text { assistant professor) }\end{array}$ & 1 & 0.32 & NA & NA \\
\hline $\begin{array}{l}\text { Ricercatori a tempo determinato L 240/10 Tipo A } \\
\text { (temporary assistant professor) }\end{array}$ & 23 & 7.35 & 212 & 6.41 \\
\hline $\begin{array}{l}\text { Ricercatori a tempo determinato L 240/10 Tipo B } \\
\text { (temporary assistant professor) }\end{array}$ & 16 & 5.11 & 157 & 4.75 \\
\hline Other (retired): & 15 & 4.79 & NA & NA \\
\hline Gender & & & & \\
\hline Male & 199 & 63.58 & 1982 & 59.95 \\
\hline Female & 113 & 36.10 & 1324 & 40.05 \\
\hline X & 1 & 0.32 & NA & NA \\
\hline NA=not available. & & & \\
\hline
\end{tabular}




\section{$3 \quad$ Results}

\subsection{Existing markets: Prices for publications}

Looking at our challenge to find the value of a publication, the publishing market certainly seems relevant. Readers and institutions pay to have access to journals, books and articles. For the fifty randomly selected journals in which at least one researcher from Sapienza published in 2018, we collected the cost of making one's article open access (see Figure 2 and Supplementary material A). Arguably, the price to make one's article open access could be interpreted as a proxy for the expected total discounted future value of publishing this study. For our illustration, this value ranges from 0 to 4786 euro with an average value of 2250 euro. All articles of a particular journal would then have the same expected value, while this value can change between journals. However, as we note in the discussion section, the academic publishing market can hardly be labeled as a perfectly competitive market.

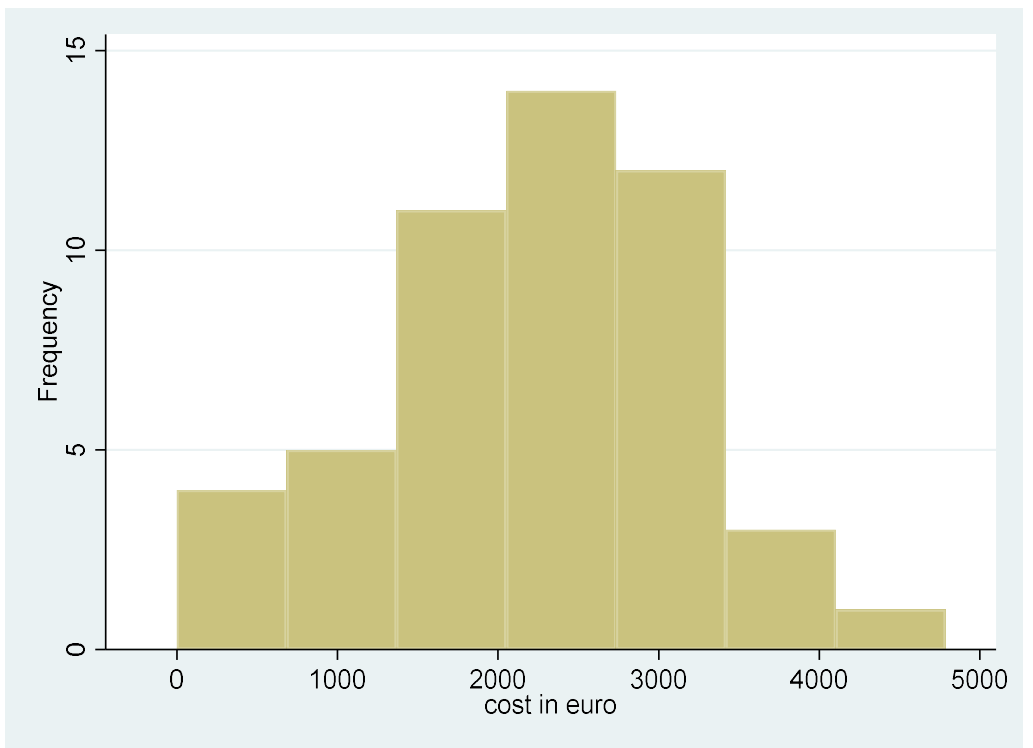

Figure 2: Open-access fees for 50 journals (data collected May 2020)

\subsection{Existing markets: Marginal production cost approach}

Next, we use the survey answers to illustrate how the value of a publication can be calculated according to this method. We asked respondents how many publications they produced in the last three years (2015, 2016 and 2017) using a categorical scale with six categories ranging from 'no 
publications' to 'more than 15 publications'. A continuous variable is created based on mid-points (see line 3 in Table 5) and the reported number of publications is divided by three to create an annual value.

We also distinguished thirteen different types of publications (Table 5). 85\% of the respondents published at least one article in an indexed (in Web of Science or Scopus) international journal, 60\% published at least one paper in a conference proceeding and 58\% published at least one chapter in an international book in the period 2015 till 2017. Books are published least frequently, as could be expected based on the amount of time needed to write, or edit, a book.

Table 5: Number of publications of the sample (2015-2017)

\begin{tabular}{|c|c|c|c|c|c|c|}
\hline Number of respondents & \multicolumn{6}{|c|}{ Number of publications } \\
\hline Publication type & zero & one & $2-5$ & $6-10$ & $11-15$ & $>15$ \\
\hline mid-point & 0 & 1 & 3.5 & 8 & 13 & 18 \\
\hline Article in indexed international journal & 47 & 24 & 74 & 68 & 33 & 67 \\
\hline Conference proceeding & 124 & 33 & 69 & 48 & 16 & 23 \\
\hline Article in 'Class $\mathrm{A}^{\prime}$ journal ${ }^{\circ}$ & 133 & 33 & 85 & 34 & 9 & 19 \\
\hline Chapter in international book & 177 & 59 & 63 & 11 & 3 & 0 \\
\hline Chapter in national book & 202 & 40 & 51 & 14 & 5 & 1 \\
\hline Article in indexed national journal & 220 & 33 & 43 & 11 & 3 & 3 \\
\hline Article in non-indexed national journal & 231 & 23 & 41 & 15 & 1 & 2 \\
\hline Article in non-indexed international journal & 243 & 40 & 24 & 5 & 0 & 1 \\
\hline Popular media (newspaper, blog, newsletter...) & 244 & 17 & 33 & 8 & 1 & 10 \\
\hline National book & 257 & 33 & 18 & 4 & 1 & 0 \\
\hline National edited book & 258 & 31 & 20 & 4 & 0 & 0 \\
\hline International edited book & 263 & 32 & 18 & 0 & 0 & 0 \\
\hline International book & 279 & 23 & 9 & 1 & 1 & 0 \\
\hline
\end{tabular}

${ }^{\circ}$ A class A journal is defined by ANVUR as being comparable to indexed journals of higher quartile (Q1) for disciplines where bibliometric indices are less useful.

Table 6: Time allocation ( $\%$ of a year) of respondents

\begin{tabular}{|l|c|c|c|c|c|}
\hline & Mean & Median & Minimum & Maximum & Std Dev \\
\hline Teaching & 36.60 & 35 & 0 & 90 & 14.11 \\
\hline Research & 36.59 & 35 & 0 & 80 & 15.88 \\
\hline Administration & 15.06 & 10 & 0 & 70 & 11.71 \\
\hline Third mission & 7.85 & 5 & 0 & 50 & 9.37 \\
\hline Other & 3.90 & 0 & 0 & 95 & 10.36 \\
\hline
\end{tabular}


Table 7: Estimated gross annual salary paid by Sapienza University

\begin{tabular}{|l|c|}
\hline & $\begin{array}{c}\text { Estimated gross annual } \\
\text { salary (in euro)* }\end{array}$ \\
\hline Full professor & 87500 \\
\hline Associate professor & 59000 \\
\hline Assistant professor full time (Ricercatore) & 44200 \\
\hline Assistant professor temporary (Ricercatori a tempo determinate) & 35000 \\
\hline Contract professor (Professori incaricati) & $10000^{\circ}$ \\
\hline Other (retired) & 0 \\
\hline
\end{tabular}

* Amount without the gross expenses of the University. Average of the years 2015, 2016 and 2017.

${ }^{\circ}$ No information about the gross salary was available for this group of professors. As they typically work part-time, we arbitrarily put their estimated annual salary at 10000 euro per year.

In the survey, we also asked respondents to provide an estimate of their time allocation in one year (i.e. 100\%) over the following activities: teaching, research, administration, third mission (service, consultancy...), and other. We found a large variety in the time allocation of our sample (Table 6). As a next step, we need an estimate of the gross annual salary paid by the university (Table 7). Based on the time allocation and the gross annual wage per function, a weighted gross annual wage is calculated to reflect that only part of a professor's time is used for research. As we do not have information on individual wages but we do know respondents' function, we use the average gross annual wage per function (Table 7).

Based on these data, a value of a publication could be derived as a unit production cost (UPC) of gross annual salary times the share of time spent on research divided by the number of publications. Note that no UPC can be calculated for researchers with zero publications in a particular category. We create four different groups of publications to check the robustness of our approach (see columns 1 and 2 in Table 8). Firstly, we only include journal articles and obtain a median value of approximately 5500 euro per publication. Secondly, chapters in books and conference proceedings are added to the journal articles to create a new group called 'Publication 1'. The median value of a publication in this group amounts to 3440 euro. Thirdly, we add published books to the group 'Publication 2' and obtain a median value of slightly below 3400 euro. Finally, including also edited books ('Publication 3), leads to a median value of slightly above 3300 euro per publication.

As not all types of publications are directly comparable, weights can be used to assign a relative value to each publication type. At the level of an individual researcher, citations or altmetric scores can be used. Such a weighing approach would then lead to higher values for publications that receive 
higher citations or altmetric scores over a certain period. This immediately points to a downside of this approach as the biases present in the distribution of citations (Rousseau et al. 2018) would transfer to the distribution of values of publications. For example, publications presenting a critical literature review would be valued more as they tend to be cited more frequently. Furthermore, it could also be desirable to take the number of co-authors into account in this weighing process. This may, for instance, lead to higher values for multi-author publications than for single-author publications when collaboration leads to more time spend on the publication (e.g. each author carefully reads to the text and revises where necessary) than the time spend on the publication by a researcher working alone.

Table 8: Value in euro of a publication expressed as Unit Production Cost - UPC (weighted values between brackets)

\begin{tabular}{|c|c|c|c|c|c|c|}
\hline & & Mean & Median & Min. & Max. & \# Obs \\
\hline Articles & $\begin{array}{l}\text { - Article in indexed international journal (5) } \\
\text { - Article in indexed national journal (5) } \\
\text { - Article in non-indexed national journal (25) } \\
\text { - Article in non-indexed international journal (25) }\end{array}$ & $\begin{array}{c}9282 \\
(1478)\end{array}$ & $\begin{array}{l}5446 \\
(875)\end{array}$ & 0 & $\begin{array}{l}105000 \\
(18375)\end{array}$ & 296 \\
\hline Publication 1 & $\begin{array}{l}\text { - } \\
\text { - } \quad \text { Conficles } \\
\text { - } \quad \text { Chapter in international book (10) } \\
\text { - } \quad \text { Chapter in national book (10) }\end{array}$ & $\begin{array}{l}5862 \\
(680)\end{array}$ & $\begin{array}{l}3442 \\
(190)\end{array}$ & 0 & $\begin{array}{c}78750 \\
(15750)\end{array}$ & 307 \\
\hline Publication 2 & $\begin{array}{ll}\text { - } & \text { Publication } 1 \\
\text { - } & \text { National book (1) } \\
\text { - } & \text { International book (1) }\end{array}$ & $\begin{array}{l}5630 \\
(685)\end{array}$ & $\begin{array}{l}3397 \\
(189)\end{array}$ & 0 & $\begin{array}{c}78750 \\
(15750)\end{array}$ & 308 \\
\hline Publication 3 & $\begin{array}{l}\text { - } \quad \text { Publication } 2 \\
\text { - } \quad \text { National edited book (20) } \\
\text { - } \text { International edited book (20) }\end{array}$ & $\begin{array}{l}5383 \\
(632)\end{array}$ & $\begin{array}{l}3315 \\
(184)\end{array}$ & 0 & $\begin{array}{c}78750 \\
(15750)\end{array}$ & 308 \\
\hline
\end{tabular}

As we do not have information on each publication at the individual level, we illustrate this by assigning a general value for each publication type. Bourke and Butler (1996) study a database containing 30000 publications by Australian research institutions published between 1980-1994. Even though this study is clearly outdated and does not capture recent trends such as digitalization and internationalization, we could find no other source with average citation rates for different publication types across all disciplines. Bourke and Butler (1996) report the following citation rates: books received 64.3 citations on average, edited books 3.5, book chapters 7.2, SCI articles 13.7, non-SCI 
articles 2.4, conference papers 1.1 and other publications 0.7 citations. From this we derive the following rule of thumb: books are 5 times more likely to be cited than indexed articles, 25 times more likely to cited than non-indexed articles, 10 times more likely to be cited than book chapters, 20 times more likely than edited books and 60 times more likely to be cited than conference proceedings. Using these weights, leads to the values between brackets in Table 8. As expected, this weighing leads to lower values for all publications types.

\subsection{Hypothetical markets: Discrete choice experiment}

Considering all choice cards presented to the respondents, one of the publication options was selected in $59 \%$ of the cases, the funding opportunity was selected in $26 \%$ of the cases and the opt-out was selected in $15 \%$ of the cases. We used Stata to estimate a conditional logit model based on dummy coding for the categorical attributes (reference categories are indicated in Table 2). Table 9 presents the estimation results including WTP (willingness to pay) estimates. The estimated coefficients have the expected signs, however several were not statistically significant.

Looking at the type of publication, we find that respondents seem indifferent between a chapter in a national book (reference category) and an article in a non-indexed national journal. An article in a non-indexed international journal is valued slightly more (at 10\% significance level), keeping all else constant. A contribution to a conference proceeding or a chapter in an international book is both valued more, and, unsurprisingly, an article in an indexed journal is valued highest. This allows us to calculate WTP values of around 8300 euro for an article in an indexed journal, around 4500 euro for a chapter in an international book, and around 3600 euro for a contribution in a conference proceeding (Table 9).

The respondents also greatly valued an English publication over an Italian publication and had a clear preference for publications with a higher standing among peers. Furthermore, they seemed indifferent to the presence or type of co-authors and also to interdisciplinary collaboration. While respondents preferred more funding over less, they seemed indifferent to the amount of time needed to finish a publication. Based on the positive, significant value of the ASC, it seems that not any publication is perceived as valuable, but only specific types. This led respondents to frequently select additional funding (i.e. the opt-out). 
Table 9: Conditional logit results

\begin{tabular}{|l|ccc|ccc|}
\hline & Coeff. & robust se & p-value & WTP (in $€$ ) & $95 \%$ CI \\
\hline Conference proceeding & $0.885^{* * *}$ & 0.178 & 0.000 & 3591 & 1876 & 5306 \\
Chapter international book & $1.097^{* * *}$ & 0.150 & 0.000 & 4452 & 2795 & 6110 \\
Article non-indexed national journal & 0.215 & 0.188 & 0.253 & 874 & -648 & 2396 \\
Article non-indexed international journal & $0.300^{*}$ & 0.181 & 0.097 & 1220 & -280 & 2719 \\
Article in indexed journal & $2.036^{* * *}$ & 0.155 & 0.000 & 8267 & 5751 & 10782 \\
English & $0.972^{* * *}$ & 0.121 & 0.000 & 3945 & 2566 & 5323 \\
Average standing & $0.394^{* * *}$ & 0.088 & 0.000 & 1598 & 811 & 2385 \\
High standing & $0.787^{* * *}$ & 0.088 & 0.000 & 3193 & 2178 & 4209 \\
Single authored & 0.083 & 0.110 & 0.446 & 339 & -541 & 1218 \\
International co-authors & 0.094 & 0.084 & 0.261 & 383 & -287 & 1053 \\
Interdisciplinary research & -0.061 & 0.065 & 0.345 & -249 & -759 & 260 \\
Time (in months) & 0.010 & 0.025 & 0.698 & & & \\
Budget (in 100€) & $0.025^{* * *}$ & 0.003 & 0.000 & & & \\
ASC - funding option & $1.467 * * *$ & 0.258 & 0.000 & & & \\
ASC - opt out & $1.558^{* * *}$ & 0.254 & 0.000 & & & \\
\hline Obs. = 8600 (273 respondents) & & & & & & \\
Pseudo R ${ }^{2}=0.1372$ & & & & & & \\
Pseudo log lik = -2571 & & & & & & \\
\hline
\end{tabular}

Note: $* / * * / * * *$ indicates $10 \% / 5 \% / 1 \%$ statistical significance

Since it is likely that respondents have heterogeneous rather than homogeneous preferences, a latent class model is estimated to identify different groups of respondents. Based on similarities between answer patterns and membership variables, respondents are grouped in different classes. Based on the BIC (Bayesian Information Criterion) and CAIC (Consistent Akaike Information Criterion) values, the optimal number of classes is determined. For our sample, three different classes could be identified (Table 10).

The first, and smallest, class (15\% of the sample) does not seem to value publications highly nor do they seem to be interested in obtaining research funding. On the contrary, more funding is valued negatively. This implies that it is not possible to calculate WTP values for this class. Time seems to be an issue: the more time that is needed to publish, the less likely they are to opt for a publication. They prefer articles in indexed journals and conference proceedings. They like to write in English rather 
than in Italian and they like publications with high standing. Note that this class of respondents is the only group that positively values interdisciplinary research. Respondents in the first class are significantly older than those in the other classes, with an average age of 58 (Table 11). This group also reported feeling the lowest amount of 'publish or perish' pressure (Table 11).

The second class ( $45 \%$ of the sample) values articles in an indexed journal most, followed by a chapter in an international book and thirdly conference proceedings. They like publishing in English and appreciate a publication in an outlet of average or high standing. Overall, they revealed a high probability of selecting one of two publication options over funding or the opt-out. Yet, they also positively value the opportunity of receiving a higher research budget. The descriptive statistics in Table 11 reveal that this second class contains the highest percentage of respondents from social sciences and humanities.

The third respondent class ( $40 \%$ of the sample) values articles in an indexed journal significantly more than publishing a chapter in an international book or a conference proceeding. In contrast to class 2 , this group of respondents values the other publication types negatively, as is revealed by the negative coefficient for 'ASC - publication'. These respondents strongly prefer to publish in English and in outlets with average or high standing among peers. Overall, this class has the highest WTP values and thus values certain types of publications, and especially, articles in indexed journals most. This class contains the highest percentage of respondents from engineering \& technology and from the exact sciences (Table 11). The respondents have the lowest average age and are most open to collaborating with other disciplines, departments or nationalities (Table 11). 
Table 10: Latent class results

\begin{tabular}{|c|c|c|c|c|c|c|c|c|c|c|c|c|c|}
\hline \multirow[b]{2}{*}{ Choice } & \multicolumn{3}{|c|}{ class 1} & \multicolumn{5}{|c|}{ class 2} & \multicolumn{5}{|c|}{ class 3} \\
\hline & coeff & se & $\mathrm{p}$-value & coeff & se & p-value & WTP & $95 \% \mathrm{CI}$ & coeff & se & p-value & WTP & $95 \% \mathrm{CI}$ \\
\hline Conference proceeding & $1.434 * *$ & 0.574 & 0.013 & $0.507 * *$ & 0.216 & 0.019 & 1579 & $49 \quad 3110$ & $1.797 * *$ & 0.905 & 0.047 & 3163 & $46 \quad 6280$ \\
\hline Chapter international book & 0.705 & 0.585 & 0.228 & $0.965 * * *$ & 0.200 & 0.000 & 3005 & 12134797 & $2.120 * *$ & 0.850 & 0.013 & 3732 & $826 \quad 6637$ \\
\hline $\begin{array}{l}\text { Article non-indexed national } \\
\text { journal }\end{array}$ & -0.240 & 0.740 & 0.746 & 0.003 & 0.234 & 0.990 & 9 & -14171434 & 0.803 & 0.965 & 0.405 & 1413 & -18824708 \\
\hline $\begin{array}{l}\text { Article non-indexed } \\
\text { international journal }\end{array}$ & 0.159 & 0.531 & 0.765 & 0.241 & 0.202 & 0.234 & 749 & $\begin{array}{ll}-561 & 2059\end{array}$ & 0.278 & 0.842 & 0.742 & 489 & -24063383 \\
\hline English & $2.156^{* * *}$ & 0.485 & 0.000 & $0.535 * * *$ & 0.110 & 0.000 & 1664 & 7442585 & $2.875 * * *$ & 0.430 & 0.000 & 5061 & 35046618 \\
\hline Average standing & 0.323 & 0.368 & 0.380 & $0.351 * * *$ & 0.117 & 0.003 & 1094 & 2551933 & $1.146^{* * *}$ & 0.269 & 0.000 & 2017 & 10742961 \\
\hline High standing & $1.190 * * *$ & 0.335 & 0.000 & $0.746^{* * *}$ & 0.121 & 0.000 & 2323 & 12103436 & $1.763 * * *$ & 0.291 & 0.000 & 3104 & 20784129 \\
\hline Single authored & -0.263 & 0.401 & 0.511 & 0.238 & 0.145 & 0.100 & 741 & $\begin{array}{ll}-207 & 1689\end{array}$ & 0.039 & 0.253 & 0.878 & 68 & -806943 \\
\hline International co-authors & -0.370 & 0.314 & 0.239 & 0.161 & 0.104 & 0.123 & 501 & -1741175 & 0.062 & 0.216 & 0.773 & 110 & -636856 \\
\hline Interdisciplinary research & $0.606 * *$ & 0.279 & 0.030 & -0.123 & 0.100 & 0.219 & -384 & -1001233 & -0.219 & 0.216 & 0.311 & -385 & -1110340 \\
\hline Time (in months) & $-0.165 *$ & 0.093 & 0.075 & 0.016 & 0.032 & 0.628 & & & 0.077 & 0.082 & 0.351 & & \\
\hline ASC - publication & $-4.120 * * *$ & 0.803 & 0.000 & $0.694 * *$ & 0.315 & 0.028 & & & $-5.580 * * * *$ & 1.166 & 0.000 & & \\
\hline Class share $(\%)$ & 0.152 & & & 0.447 & & & & & 0.401 & & & & \\
\hline \multicolumn{14}{|l|}{ membership } \\
\hline Medical sciences & 0.027 & 0.465 & 0.954 & 0.185 & 0.365 & 0.613 & & & & & & & \\
\hline Social sciences & 1.115 & 0.963 & 0.247 & $2.237 * * *$ & 0.659 & 0.001 & & & & & & & \\
\hline Humanities & $1.910 *$ & 1.059 & 0.071 & $2.852 * * *$ & 0.943 & 0.002 & & & & & & & \\
\hline Age of respondents (in years) & $0.094 * * *$ & 0.025 & 0.000 & $0.037 * *$ & 0.018 & 0.041 & & & & & & & \\
\hline constant & $-6.240 * * *$ & 1.411 & 0.000 & $-2.336 * *$ & 1.016 & 0.021 & & & & & & & \\
\hline \multicolumn{14}{|l|}{ Obs. $=8600$ (273 respondents) } \\
\hline
\end{tabular}


Table 21: Descriptive statistics of the three classes

\begin{tabular}{|c|c|c|c|c|c|c|}
\hline & Class 1 & class 2 & Class 3 & \multicolumn{3}{|c|}{ t-test one-sided } \\
\hline$\%$ & $(\mathrm{~N}=40)$ & $(\mathrm{N}=122)$ & $(\mathrm{N}=111)$ & $1 \mathrm{v} 2$ & $1 \mathrm{v} 3$ & $2 \mathrm{v} 3$ \\
\hline Age (in years) & 58.10 & 52.50 & 50.20 & $* * *$ & $* * *$ & $* *$ \\
\hline Male & 0.58 & 0.62 & 0.66 & ns & $\mathrm{ns}$ & ns \\
\hline Engineering \& technology & 0.23 & 0.20 & 0.38 & ns & $* *$ & $* * *$ \\
\hline Medical sciences & 0.35 & 0.26 & 0.34 & ns & ns & $*$ \\
\hline Exact sciences & 0.23 & 0.15 & 0.23 & ns & ns & $*$ \\
\hline Social sciences & 0.08 & 0.17 & 0.04 & * & ns & $* * *$ \\
\hline Humanities & 0.13 & 0.22 & 0.02 & $*$ & $* * *$ & $* * *$ \\
\hline Full professor & 0.23 & 0.20 & 0.14 & ns & $*$ & $*$ \\
\hline Associate professor & 0.40 & 0.30 & 0.49 & ns & ns & $* * *$ \\
\hline Assistant professor (full time) & 0.25 & 0.30 & 0.16 & ns & ns & $* * *$ \\
\hline Assistant professor (part time) & 0.08 & 0.11 & 0.19 & ns & $* *$ & $* *$ \\
\hline Contract professor & 0.00 & 0.03 & 0.00 & ns & ns & $* * *$ \\
\hline Other & 0.05 & 0.06 & 0.03 & ns & ns & ns \\
\hline Published at least... & & & & & & \\
\hline 2 indexed articles ${ }^{\circ}$ & 0.55 & 0.59 & 0.74 & ns & $* *$ & $* * *$ \\
\hline 6 indexed articles ${ }^{\circ}$ & 0.50 & 0.45 & 0.73 & ns & $* * *$ & $* * *$ \\
\hline 2 conference proceedings ${ }^{\circ}$ & 0.40 & 0.43 & 0.59 & $\mathrm{~ns}$ & $* *$ & $* * *$ \\
\hline 1 book $^{\circ}$ & 0.33 & 0.48 & 0.25 & $* *$ & ns & $* * *$ \\
\hline 2 book chapters ${ }^{\circ}$ & 0.28 & 0.48 & 0.29 & $* *$ & ns & $* * *$ \\
\hline 1 item in popular media ${ }^{\circ}$ & 0.13 & 0.23 & 0.21 & $*$ & ns & $\mathrm{ns}$ \\
\hline Feel 'publish or perish' pressure & 0.35 & 0.59 & 0.64 & $* * *$ & $* * *$ & ns \\
\hline $\begin{array}{r}\text { Collaborate frequently with... } \\
\text { other department Sapienza }\end{array}$ & 0.30 & 0.25 & 0.44 & ns & * & $* * *$ \\
\hline other disciplines & 0.28 & 0.20 & 0.28 & ns & ns & $*$ \\
\hline other nationalities & 0.38 & 0.31 & 0.59 & ns & $* *$ & $* * *$ \\
\hline $\begin{array}{l}\text { Collaborate never with... } \\
\text { other department Sapienza }\end{array}$ & 0.18 & 0.26 & 0.14 & ns & ns & $* * *$ \\
\hline other disciplines & 0.13 & 0.17 & 0.14 & ns & ns & ns \\
\hline other nationalities & 0.00 & 0.00 & 0.00 & ns & ns & ns \\
\hline
\end{tabular}

Note: $* / * * / * * *$ indicates $10 \% / 5 \% / 1 \%$ statistical significance; $n s=$ not significant; maximum indicated in bold ${ }^{\circ}=$ in 2015,2016 and 2017 
The results reported in Tables 10 and 11 shows that the first class is a "residual class" composed by senior researchers close to retirement and medicine scholars that work mostly in the university hospital. This class has the highest percentage of ordinary professors that are used to collaborate with people from other disciplines. This is a marginal class (with only 44 scholars). The third class is composed by scholars that show an orientation towards "bibliometric indicators" such as indexed articles and conference proceedings, typical of scholars coming from engineering and natural sciences but also medicine, mostly associate professors, with the highest $\%$ of male, the highest scientific productivity and the highest collaborations. We name this class "bibliometric oriented class". It is interesting to note that there is also a small presence of social science and humanities in this class. Class 2 represents scholars coming mostly from the Humanities and Social Sciences, oriented to publish also books, book chapters and active on social media, together with indexed articles. This class has a high percentage of assistant professors, and is named "non-bibliometric oriented class". It is interesting to note that there is also a significant presence in this class of scholars belonging to engineering, medicine and natural sciences, which show the typical features of the nonbibliometric class.

\section{Discussion and critical assessment of the valuation approaches}

\subsection{Existing markets: Prices for publications}

Even though the APC values in this study are based on a relatively small sample, they are in line with the values reported by Solomon and Björk (2012). Based on the APC values for 1370 journals that published 100697 articles in 2010, they find an average APC of 906 USD and a price range between 8 and 3900 USD.

The academic publishing market is clearly not a well-functioning market in an economic sense. It can be categorized as an oligopoly with a limited number of big players such as ReedElsevier, Wiley Blackwell, Springer, and Taylor \& Francis (Larivière et al., 2015). Academic publishers have a substantial amount of market power which gives them the opportunity for price discrimination between, for example, individual and institutional subscribers (Chressantis \& Chressantis, 1993; McGuigan, 2004). Moreover, the fierce competition to get published means that academic authors are forced to carry most of the costs of writing and evaluating publications themselves and this leads to low production costs for the publishers. Even the presence of online journals and open access initiatives does not lead to a big shift in this market (McGuigan, 2004; Larivière et al., 2015). Larivière et al. (2015, p9) show that "on the whole, 
the top commercial publishers have benefited from the digital era, as it led to a dramatic increase in the share of scientific literature they published. It has also led to a greater dependence by the scientific community on these publishers". Besides, there are also externalities present in this market: publications can have substantial external benefits through sharing knowledge and advancing science (spillover effects). In conclusion, while a market for publications exists, its prices do not reflect the true value of publications due to the many market imperfections and distortions that are present. This method is thus too simplistic and its results should be treated with caution.

\subsection{Existing markets: Marginal production cost approach}

This method has some clear advantages. It is easy to calculate and the required data are easily available. This makes it a quick and cheap method to apply. Moreover, the reasoning and motivation are quite easy to explain and to understand for the general public and policymakers.

Unfortunately, several criticisms can be formulated related to this approach. While the marginal cost can be a good proxy for the value of a publication, this requires well-functioning competitive labor markets for academics. As academia is a heavily subsidized and regulated sector and transaction costs limit international mobility, this assumption of a well-functioning market is unlikely to hold. As private markets can be argued to be more efficient, gross wages on private markets may be a better proxy for the opportunity cost of time used by researchers.

Besides labor costs, also other costs can be relevant such as software needed to run additional simulations or regressions or to generate illustrations or paying for editing and translation services.

The method proposed by Florio et al. (2016b) also has some questionable implications. Publications from countries where wages are higher would be worth more. This implies that a joint publication by a Swiss and an Italian researcher would be valued higher for the Swiss coauthor than for the Italian one. An approach leading to two values for the same paper clearly has some flaws. A Purchasing Power Parity (PPP)-like correction may be helpful. Publications from researchers with a low teaching load would be worth less than those from researchers with a high teaching load. Publications from researchers who publish less items per unit of time spent in research would be worth more than those from researchers who publish more items per unit time spent in research. Publications from retired staff would seem worthless (reflecting their zero wage cost for the university).

A correction for the quality and type of publication can be advisable. For instance, the value of an article in an international, indexed journal can be different from the value of chapter in a 
national book. The number of co-authors should also be taken into account. As a proxy for the quality of the publication, Florio et al. (2016b) used the expected number of citations to a publication as well as the number of references to other publications. We used weights based on expected citations per publication type to calculate an alternative value in Table 8 . Assigning weights is a challenge as it is well-known how difficult it is to develop an objective and comparable quality measure for publications that can be used across disciplines (e.g., Wilsdon et al., 2015).

\subsection{Hypothetical markets: Discrete choice experiments}

Since DCEs are a survey-based valuation technique, they are very flexible and can be adapted to different settings. Moreover, they allow interested stakeholders to estimate use as well as non-use values and to calculate different values for different types of publications (e.g. article vs book chapter). In addition, the value of publication characteristics such as type of coauthor, language and standing can be assessed.

However, since survey responses represent stated behavior rather than actual behavior, they can suffer from a hypothetical bias (Hensher, 2010). Especially the extent to which individuals might behave inconsistently, when they do not have to back up their choices with real commitments, is becoming a major question. Thus, DCE are said to suffer from nonconsequentialism, which may lead to over-estimation of WTP values and market shares and may undermine the external validity of DCEs (Johnston et al., 2017).

It is well established, in the stated preference literature, that the provision of information influences the responses given by survey respondents (Ajzen et al., 1996; Teisl et al., 2002; Johnston et al., 2017). In essence, the appropriate amount of information should be provided such that respondents have a clear definition of the public good that they are valuing. However, providing information about a public or private good can be viewed as persuasive communication and is likely to change these attitudes and intentions. Even though we may make every effort to produce an accurate and balanced description of the proposed transaction, the information provided will almost inevitably alter the respondents' beliefs and attitudes. The impact of information on choices is referred to as information bias, but also priming and framing effects are closely linked concepts.

Finally, it is important to note that the sampling technique and the quality of the sample are important determinants of the quality of the results from discrete choice experiments.

\subsection{Limitations}

The illustration based on Sapienza is subject to several limitations. Firstly, we are only looking at one specific university in Italy. Researchers at other universities in other countries 
may value publications differently. Secondly, our dataset contains approximately $10 \%$ of the academic staff at Sapienza and provides a biased representation of the different faculties, although not of the different functions and gender. The response was likely affected by the use of English as survey language and by the lack of reminders. To get an idea of acceptable sample sizes, power calculations show that a sample of 313 respondents out of a population of 3306 individuals leads to a margin of error of $5.27 \%$ with a $95 \%$ confidence level (Daniel \& Cross, 2018). As this calculation method is based on the assumption that the randomly selected sample has on average the same characteristics as the population and thus that no systematic biases are present, this type of power calculations is purely indicative. While explorative, the application to Sapienza still had practical relevance as indicated by the following quotes from the Deputy Rector for Research, Innovation and Technology Transfer of Sapienza ${ }^{5}$ : 'The results illustrated in the study highlight some issues of which we are already aware and that we have tried to take into account in the research policy assessment during recent years, e.g. the imperfections and distortions of prices for publications' and 'The framework proposed will be integrated into monitoring activities already implemented in Sapienza'.

Thirdly, as with all survey data, our dataset contains self-reported information and may thus be susceptible to social desirability bias and as well as hypothetical bias. The overrepresentation of researchers from the exact sciences and engineering $\&$ technology and underrepresentation of researchers from the medical sciences may influence the results although it is not a prior clear which form this influence would take. The biases related to selfreporting may lead to respondents to misrepresent their past publications or to make an unrealistic choice in the DCE. While we would all like to publish only in the top journals of our fields, this is not a realistic option and in practice, we may happily settle for a subtop journal.

Finally, it is important to note that we mainly measure the use value of publications since all respondents were users. Still, in the DCE, some part of the non-use value may have been captured. To determine the full value of a publication, other stakeholders should also be involved.

\section{Conclusion}

The main contribution of our study lays in making the challenge of measuring the value of publications in research policy assessment and funding strategies visible. In a world of scarce

\footnotetext{
${ }^{5}$ Personal communication via email, 25 August 2020.
} 
resources it is important to carefully consider funding of researchers, research institutions and research infrastructure. Thus, the call for high-quality impact assessment of research policies is increasing over time. In this paper, we analyze the little-treated issue of how the value of scientific publications can be included in such impact assessments. Although this issue is largely neglected by the existing literature, we believe its development and treatment is of considerable, almost urgent, importance for research evaluation policies. Ignoring this compelling topic does not solve the existing needs of stakeholders to attribute a value to scientific publications. As we have seen, on the contrary, simplistic and very ad hoc approaches are being used by policymakers. Thus, the main aim of this study is to inspire increased attention to this issue and to provide a critical overview of possible methods that can be used to value publications. The main characteristics of applicable methods to value scientific publications are discussed in general and illustrated for Sapienza University of Rome based on an explorative survey. Thus, we launch a call to study this critical issue in more depth, focusing on underlying methodological issues as well as the challenge of estimating values in practice.

Florio et al. (2016a) provide a first valuable study on this issue, including use and non-use value of research and using a market-based as well as a survey-based approach. We extend this framework adding a critical discussion of their approach and complementing it with two alternative methods. As such, the different approaches illustrated and compared in this study provide a next step in this search for ways to include publications and research output into evaluation projects and cost-benefit analysis. Each one has its strengths and weaknesses, which should be acknowledged. In addition, the objective and context (budget, timing) of the evaluation are relevant factors to take into account. The different approaches lead to a range of values that are fairly similar; with the market-based approach leading to an average estimate of 2250 euro (with a range between 0 and 4786 euro) per article, the production cost approach to an estimate of 3300 - 5000 euro per publication, and the discrete choice experiment to an estimate of $3600-8300$ euro per international publication. That the highest values were obtained by the DCE approach can be related to several reasons. Open access fees are real prices available on the market, while the DCE values are based on hypothetical choices. The production costs approach was based on familiar questions which could easily be answered, while the DCE approach was unfamiliar to the majority of the respondents. Moreover, the DCE values can include not only use values but also part of the non-values, while the other approaches only capture use values.

When using these kinds of monetary values for scientific publications, sensitivity analysis and possibly simulations are required to assess the impact of this valuation on the policy 
decision. CBA is a decision-support tool and is meant to help organize a debate over an issue. The systematic categorization of all impacts (i.e. costs and benefits) and a clearly motivated comparison of these impacts expressed in the same utility units (i.e. money) provide a rich source of inputs for public and private decision-makers. Yet some caveats need to be made. The implementation of a CBA also presents challenges. It is not always easy to obtain the necessary data to estimate the size of the effects. The achievement of useful results depends to a large extent on the use of correct valuation methods. Moreover, a CBA does not provide insight into the optimal timing of projects and the distribution of social welfare impacts must be considered separately (Nyborg, 2012).

Different points of view can also be implemented. Besides the perspective of the researchers, considered in this paper, other perspectives including policymakers and the general public may be considered. While the survey-based approach is very flexible and adaptable to different contexts, it is time-consuming.

Having said that, there is still a need to address the open, but very relevant, issue of monetary evaluation of scientific publication with further methodological and empirical works, keeping aside ideological oppositions, to accomplish policy and stakeholders needs, as witnessed for instance by DG Regio (2014), that are going to increase in the near future and require an in-depth investigation of these issues. Future research could further explore the heterogeneity of preference among researchers (e.g., different career phases, different disciplines or cultural differences) or among universities (e.g., student-oriented versus research-oriented or generalist versus specialist institutions). In order to better assess the possible biases of the different valuation approaches, a comparison between self-reported with official data on publication behavior would be valuable. Moreover, it would be interesting to obtain detailed information regarding the publication profiles of individual researchers to study how publication characteristics such number of co-authors influence the estimation of the value of publications. In this paper, we offer a critical contribution to highlight the limits of current approaches and to stress the need for further research on this topic.

Finally, the most important point that we need to understand is what the value of publications is for researchers, institutions, other stakeholders and society before coming back to the measurement of these different aspects of value. This would require starting from fundamentals to provide useful input for policy making and impact assessments. 


\section{Contribution statement:}

SR has developed the research set-up, designed the first draft of the survey, executed the statistical analysis, wrote the first draft of the text and has coordinated the revisions. GC has helped to improve the survey, collected the survey data and the additional information regarding Sapienza and has provided feedback on the text. CD has developed the research setup, helped to improve the survey, collected the survey data and substantially revised the text.

\section{References}

Ajzen, I., Brown, T.C., \& Rosenthal, L.H. (1996). Information bias in contingent valuation: effects of personal relevance, quality of information, and motivational orientation. Journal of Environmental Economics and Management, 30(1), 43-57.

Alberini, A., Longo, A., \& Veronesi, M. (2007). Basic statistical models for stated choice studies. In B. Kanninen (Ed.), Valuing environmental amenities using stated choice studies: A common sense guide to theory and practice, 8, 203-227. Springer.

Amaya-Amaya, M., Gerard, K. \& M. Ryan (2008). Discrete choice experiments in a nutshell. In: M. Ryan, K. Gerard and M. Amaya-Amaya (eds.), Using discrete choice experiments to value health and health care, 13-46. Springer.

Aversano, N., Manes-Rossi, F., \& Tartaglia-Polcini, P. (2018). Performance measurement systems in universities: a critical review of the Italian system. In Outcome-based performance management in the public sector (pp. 269-287). Springer, Cham.

Battistoni, G., Genco, M., Marsilio, M., Pancotti, C., Rossi, S., \& Vignetti, S. (2016). Costbenefit analysis of applied research infrastructure. Evidence from health care. Technological Forecasting and Social Change, 112, 79-91

Bornmann, L. (2013). What is societal impact of research and how can it be assessed? A literature survey. Journal of the American Society for Information Science and Technology, 64(2), 217-233.

Bornmann, L., \& Marx, W. (2014). How should the societal impact of research be generated and measured? A proposal for a simple and practicable approach to allow interdisciplinary comparisons. Scientometrics, 98(1), 211-219.

Boxall, P.C. \& Adamowicz, W.L. (2002). Understanding heterogeneous preferences in random utility models: A latent class approach. Environmental and Resource Economics, 23, 421446

Bourke, P., \& Butler, L. (1996). Publication types, citation rates and evaluation. Scientometrics, 37(3), 473-494.

Bozeman, B., \& Sarewitz, D. (2011). Public value mapping and science policy evaluation. Minerva, 49(1), 1-23.

Castelnovo, P., Florio, M., Forte, S., Rossi, L., \& Sirtori, E. (2018). The economic impact of technological procurement for large-scale research infrastructures: Evidence from the Large Hadron Collider at CERN. Research Policy, 47(9), 1853-1867.

Catalano, G., Florio, M., \& Giffoni, F. (2016). Willingness to pay for basic research: a contingent valuation experiment on the large hadron collider. arXiv preprint arXiv: 1603.03580

Chressanthis, G.A., \& Chressanthis, J. (1993). Publisher monopoly power and third-degree price discrimination of scholarly journals. Technical Services Quarterly, 11(2), 13-36.

Daniel, W.W., \& Cross, C.L. (2018). Biostatistics: a foundation for analysis in the health sciences. Wiley. 
Daraio, C., Lenzerini, M., Leporelli, C., Moed, H.F., Naggar, P., Bonaccorsi, A., Bartolucci, A. (2016). Data integration for research and innovation policy: an Ontology-Based Data Management approach. Scientometrics, 106(2), 857-871.

De Rus, G. (2010). Introduction to cost-benefit analysis. Edward Elgar.

DG Regio (2014). Guide to cost benefit analysis of investment projects. http://ec.europa.eu/regional_policy/sources/docgener/studies/pdf/cba_guide.pdf

Diamond, A.M., Jr. (1985) The money value of citations to single-authored and multipleauthored articles. Scientometrics, 8 (5-6), 315-320.

Florio, M., Forte, S., \& Sirtori, E. (2016a). Forecasting the socio-economic impact of the Large Hadron Collider: A cost-benefit analysis to 2025 and beyond. Technological Forecasting and Social Change, 112, 38-53.

Florio, M., Forte, S., Pancotti, C., Sirtori, E., \& Vignetti, S. (2016b). Exploring cost-benefit analysis of research, development and innovation infrastructures: an evaluation framework. arXiv preprint arXiv:1603.03654.

García-Romero, A., Escribano, Á., \& Tribó, J.A. (2017). The impact of health research on length of stay in Spanish public hospitals. Research Policy, 46(3), 591-604.

Geuna, A., \& Martin, B. . (2003). University research evaluation and funding: An international comparison. Minerva, 41(4), 277-304.

Gibbons, M., Limoges, C., Nowotny, H., Schwartzman, S., Scott, P., Trow, M. (1994). The new production of knowledge: The dynamics of science and research in contemporary societies. Sage.

Greenhalgh, T., Raftery, J., Hanney, S., \& Glover, M. (2016). Research impact: a narrative review. BMC medicine, 14(1), 78 .

Hensher, D.A. (2010). Hypothetical bias, choice experiments and willingness to pay. Transportation Research Part B, 44(6), 735-752.

Hensher, D., Louviere, J. \& Swait, J. (1999). Combining sources of preference data. Journal of Econometrics, 89, 197-222.

Hill, S. (2016). Assessing (for) Impact: Future assessment of the societal impact of research, Palgrave Communications, 2: 16073.

Johnston, R.J., Boyle, K.J., Adamowicz, W., Bennett, J., Brouwer, R., Cameron, T.A., Hanemann, W.M., Hanley, N., Ryan, M., Scarpa, R. \& Tourangeau, R. (2017). Contemporary guidance for stated preference studies. Journal of the Association of Environmental and Resource Economists, 4(2), 319-405.

Larivière, V., Haustein, S., \& Mongeon, P. (2015). The oligopoly of academic publishers in the digital era. PloS one, 10(6), e0127502.

Lenzerini M. \& Daraio C. (2019), Challenges, Approaches and Solutions in Data Integration for Research and Innovation, in Springer Handbook of Science and Technology Indicators edited by Glänzel W., Moed H.F., Schmoch H. and Thelwall M., 397-420.

Louviere, J.J. \& Hensher, D.A. (1982). On the design and analysis of simulated choice or allocation experiments in travel choice modeling. Transportation Research Record, 890, 11-17.

Louviere, J.J. \& Woodworth, G. (1983). Design and analysis of stimulated choice experiments or allocation experiments: An approach based on aggregate data. Journal of Marketing Research, 20, 350-367.

Mangham, L. J., Hanson, K., \& McPake, B. (2009). How to do (or not to do)... Designing a discrete choice experiment for application in a low-income country. Health Policy and Planning, 24(2), 151-158.

Martin, B. R., \& Tang, P. (2007). The benefits from publicly funded research. Science Policy Research Unit, University of Sussex. 
McGuigan, G.S. (2004). Publishing perils in academe: The serials crisis and the economics of the academic journal publishing industry. Journal of Business \& Finance Librarianship, $10(1), 13-26$.

Molas-Gallart, J., \& Tang, P. (2011). Tracing 'productive interactions' to identify social impacts: an example from the social sciences. Research Evaluation, 20(3), 219-226.

Nowotny, H., Scott, P., \& Gibbons, M. (2001). Re-thinking science: Knowledge and the public in an age of uncertainty. Cambridge.

Nowotny, H., Scott, P., \& Gibbons, M. (2003). Introduction: Mode 2'Revisited: The New Production of Knowledge. Minerva, 41(3), 179-194.

Nyborg, K. (2012). The ethics and politics of environmental cost-benefit analysis. Routledge

Pearce, D., Atkinson, G. \& Mourato, S. (2006). Cost-benefit analysis and the environment. OECD.

Poelmans, E. \& Rousseau, S. (2015). Factors determining authors' willingness to wait for editorial decisions from economic history journals. Scientometrics, 102(2), 1347-1374

Rousseau, R., Egghe, L., \& Guns, R. (2018). Becoming metric-wise: A bibliometric guide for researchers. Chandos Publishing.

Rousseau, S. \& Rousseau, R. (2012). Interactions between journal attributes and authors' willingness to wait for editorial decisions. Journal of the American Society for Information Science and Technology, 63(6), 1213-1225.

Rousseau, S. \& Tejerizo Fuertes, A. (2020). Country borders and the value of scuba diving in an estuary. Ocean and Coastal Management, 184, nr. 105002 (doi: 10.1016/j.ocecoaman.2019.105002)

Salter, A.J., \& Martin, B.R. (2001). The economic benefits of publicly funded basic research: a critical review. Research Policy, 30(3), 509-532.

Solomon, D.J., \& Björk, B.C. (2012). A study of open access journals using article processing charges. Journal of the American Society for Information Science and Technology, 63(8), 1485-1495.

Spaapen, J., \& Van Drooge, L. (2011). Introducing 'productive interactions' in social impact assessment. Research Evaluation, 20(3), 211-218.

Teisl, M.F., Roe, B., \& Hicks, R.L. (2002). Can eco-labels tune a market? Evidence from dolphin-safe labeling. Journal of Environmental Economics and Management 43, 339-359

Train, K.E. (2003). Discrete Choice Methods with Simulations (1 ed.). Cambridge: Cambridge University Press.

Tuckman, H.P., \& Leahey, J. (1975). What is an article worth? Journal of Political Economy, 83(5), 951-967.

Waltman, L., van Eck, N.J., \& Wouters, P. (2013). Counting publications and citations: Is more always better? Journal of Informetrics, 7(3), 635-641.

Wilsdon, J., et al. (2015). The Metric Tide: Report of the Independent Review of the Role of Metrics in Research Assessment and Management. DOI: 10.13140/RG.2.1.4929.1363

Wise, W.S. (1975). The role of cost-benefit analysis in planning agricultural R \& D programmes. Research Policy, 4(3), 246-261. 


\section{Supplementary material A - List of randomly selection journals}

\begin{tabular}{|c|c|c|}
\hline ID Journal & cost of open access & cost (euro) \\
\hline 17 Parasites \& Vectors & 1990 EUR & 1990 \\
\hline 141 Frontiers in Pediatrics & 2950 USD & 2715 \\
\hline 426 Journal of Bone and Mineral Research & 2500 EUR & 2500 \\
\hline 590 Blood & 75 USD per page* & 552 \\
\hline 643 Vaccine & 2950 USD & 2715 \\
\hline 1004 Journal of Thoracic Disease & 1390 USD & 1279 \\
\hline 1024 Nutrients & $2000 \mathrm{CHF}$ & 1899 \\
\hline 1215 NPJ Schizophrenia & 2680 EUR & 2680 \\
\hline 1537 International Journal of Fatigue & 2970 USD & 2733 \\
\hline 1897 European Respiratory Journal & 2100 EUR & 2100 \\
\hline 1986 PeerJ & 1195 USD & 1100 \\
\hline 2355 Cognitive Processing & 2570 EUR & 2570 \\
\hline 2708 Journal of Nephrology & 3060 EUR & 3060 \\
\hline 2901 Neuropharmacology & 3340 USD & 3074 \\
\hline 3079 Journal of Cleaner Production & 3740 USD & 3442 \\
\hline 3163 Journal of Physics-Condensed Matter & 2315 EUR & 2315 \\
\hline 3316 Sensors & $2000 \mathrm{CHF}$ & 1899 \\
\hline 3512 Journal of Pediatric Orthopaedics-Part B & 2850 USD & 2623 \\
\hline 3714 Ecography & 1900 EUR & 1900 \\
\hline 3902 Neuromuscular Disorders & 3200 USD & 2945 \\
\hline 3936 Oncogene & 3580 EUR & 3580 \\
\hline 4253 Journal of Functional Analysis & 1850 USD & 1703 \\
\hline 4256 Cancer Cell & 5200 USD & 4786 \\
\hline 4433 European Journal of Mineralogy & $140+140$ EUR per page* & 1260 \\
\hline 4856 Journal of Hepatology & 3000 USD & 2761 \\
\hline 5027 Revista Portuguesa De Cardiologia & 3000 USD & 2761 \\
\hline 5057 Annals of Rehabilitation Medicine-Arm & $400 \mathrm{USD}$ & 368 \\
\hline 5211 Radiology & 3000 USD & 2761 \\
\hline 5295 Classical and Quantum Gravity & 2315 EUR & 2315 \\
\hline 5436 Frontiers in Immunology & 2950 USD & 2715 \\
\hline 5469 European Journal of Ophthalmology & 3000 EUR & 3000 \\
\hline 5494 Journal of Pediatrics & 3750 USD & 3451 \\
\hline 5506 Neoplasia & 2500 USD & 2301 \\
\hline 5639 Current Oncology Reports & 3060 EUR & 3060 \\
\hline 6129 Taxon & 1800 EUR & 1800 \\
\hline 6259 Annals of The Rheumatic Diseases & $2400 \mathrm{GBP}$ & 2740 \\
\hline 6304 Blood Cells Molecules and Diseases & 3300 USD & 3037 \\
\hline 6536 Hagiographica & na & na \\
\hline 6643 International Journal of Environment and Pollution & 3000 USD & 2761 \\
\hline 6805 Bruniana \& Campanelliana & 1750 EUR & 1750 \\
\hline 6864 Journal of Alzheimers Disease & 1250 EUR & 1250 \\
\hline 6894 Revista Digital De Iconografia Medieval & 0 & 0 \\
\hline $\begin{array}{l}7043 \begin{array}{l}\text { Enthymema-International Journal of Literary } \\
\text { Criticism Literary Theory and Philosophy of } \\
\text { Literature }\end{array}\end{array}$ & 0 & 0 \\
\hline 7340 Geofluids & 1650 USD & 1518 \\
\hline 7579 Meteorologische Zeitschrift & $140+119$ EUR per page* & 1092 \\
\hline 7715 Quaderni Urbinati Di Cultura Classica & 1750 EUR & 1750 \\
\hline
\end{tabular}




\begin{tabular}{|l|l|l|l|}
\hline 7800 & Advances in Mathematical Physics & 2050 USD & 1887 \\
\hline 7979 & Acta Chirurgica Belgica & 2495 EUR & 2495 \\
\hline 8058 & Shock and Vibration & 2200 USD & 2025 \\
\hline 8093 & Current Alzheimer Research & 3195 USD & 2940 \\
\hline 8239 & Neurological Sciences & 2570 EUR & 2570 \\
\hline
\end{tabular}

* In order to calculate the full open access cost, we assumed that an article consists of 8 pages.

\section{Supplementary material B - Design of choice cards generated by Ngene}

The 24 choice cards that are ordered in three blocks of eight profiles are presented on the next page. The coding used is defined below.

\begin{tabular}{|l|l|l|}
\hline Attributes & Attribute levels & Code \\
\hline Outlet & Non-indexed national journal (reference) & 0 \\
& Contribution published in Conference proceedings & 1 \\
& Chapter in national book & 2 \\
& Chapter in international book & 3 \\
& Non-indexed international journal & 4 \\
& Indexed (WoS, Scopus) journal & 5 \\
\hline Language & Italian (reference) & 0 \\
& English & 1 \\
\hline Standing/status of publication & Low (reference) & 0 \\
& Average & 1 \\
& High & 2 \\
\hline Co-authors & No co-authors - single author & 0 \\
& Only local co-author(s) (reference) & 1 \\
& At least one international co-author & 2 \\
\hline Discipline co-authors & All authors same discipline (reference) & 0 \\
& At least one author from another discipline & 1 \\
\hline $\begin{array}{l}\text { Time needed to write and revise } \\
\text { the publication (FTE; not } \\
\text { including waiting time) }\end{array}$ & $1 ; 1.5 ; 2 ; 3 ; 4 ; 5$ months & \\
\hline Budget & & \\
\hline
\end{tabular}




\begin{tabular}{|c|c|c|c|c|c|c|c|c|c|c|c|c|c|c|}
\hline choice card & outlet & language & $\begin{array}{c}\text { Alte } \\
\text { status }\end{array}$ & $\begin{array}{l}\text { native } A \\
\text { coauthors }\end{array}$ & discipline & time & outlet & language & $\begin{array}{c}\text { Alte } \\
\text { status }\end{array}$ & $\begin{array}{l}\text { rnative B } \\
\text { coauthors }\end{array}$ & discipline & time & $\begin{array}{c}\text { Funding } \\
\text { budget }\end{array}$ & Block \\
\hline 1 & 2 & 1 & 1 & 2 & 0 & 2 & 3 & 1 & 2 & 1 & 1 & 3 & 2500 & 1 \\
\hline 7 & 1 & 1 & 0 & 1 & 0 & 1.5 & 2 & 1 & 2 & 2 & 1 & 4 & 5000 & 1 \\
\hline 9 & 4 & 1 & 2 & 1 & 1 & 5 & 5 & 0 & 1 & 2 & 0 & 1 & 3500 & 1 \\
\hline 15 & 3 & 0 & 1 & 0 & 0 & 1.5 & 5 & 1 & 2 & 2 & 0 & 4 & 5000 & 1 \\
\hline 17 & 2 & 1 & 0 & 0 & 0 & 3 & 3 & 1 & 1 & 1 & 0 & 2 & 3500 & 1 \\
\hline 18 & 5 & 0 & 2 & 2 & 1 & 2 & 3 & 1 & 0 & 0 & 0 & 3 & 500 & 1 \\
\hline 19 & 5 & 0 & 2 & 0 & 0 & 2 & 0 & 1 & 0 & 2 & 1 & 3 & 500 & 1 \\
\hline 20 & 5 & 1 & 0 & 2 & 1 & 4 & 2 & 1 & 2 & 1 & 0 & 1.5 & 500 & 1 \\
\hline 2 & 3 & 1 & 2 & 2 & 0 & 2 & 5 & 1 & 0 & 0 & 0 & 4 & 5000 & 2 \\
\hline 4 & 1 & 0 & 0 & 2 & 0 & 4 & 5 & 1 & 1 & 1 & 1 & 1 & 1500 & 2 \\
\hline 5 & 0 & 1 & 1 & 1 & 1 & 1.5 & 4 & 0 & 0 & 2 & 0 & 3 & 2500 & 2 \\
\hline 10 & 1 & 1 & 1 & 1 & 1 & 3 & 0 & 0 & 2 & 0 & 0 & 2 & 3500 & 2 \\
\hline 11 & 5 & 1 & 1 & 2 & 0 & 4 & 4 & 0 & 0 & 1 & 1 & 1 & 3500 & 2 \\
\hline 14 & 3 & 0 & 1 & 2 & 0 & 5 & 5 & 1 & 0 & 0 & 0 & 1.5 & 500 & 2 \\
\hline 22 & 3 & 1 & 2 & 2 & 1 & 1 & 4 & 0 & 1 & 1 & 0 & 5 & 1500 & 2 \\
\hline 23 & 3 & 1 & 0 & 1 & 0 & 3 & 1 & 0 & 1 & 2 & 1 & 2 & 1500 & 2 \\
\hline 3 & 4 & 1 & 1 & 0 & 0 & 1 & 3 & 0 & 0 & 1 & 1 & 5 & 2500 & 3 \\
\hline 6 & 2 & 0 & 0 & 1 & 1 & 4 & 4 & 1 & 2 & 2 & 0 & 1.5 & 2500 & 3 \\
\hline 8 & 0 & 0 & 2 & 1 & 0 & 1 & 4 & 1 & 1 & 2 & 1 & 5 & 1500 & 3 \\
\hline 12 & 4 & 1 & 2 & 1 & 0 & 5 & 2 & 1 & 1 & 2 & 1 & 1 & 2500 & 3 \\
\hline 13 & 0 & 1 & 1 & 0 & 0 & 5 & 1 & 1 & 2 & 1 & 0 & 1.5 & 1500 & 3 \\
\hline 16 & 5 & 0 & 2 & 1 & 1 & 3 & 0 & 1 & 0 & 2 & 0 & 2 & 5000 & 3 \\
\hline 21 & 5 & 1 & 0 & 1 & 0 & 1.5 & 1 & 1 & 2 & 0 & 0 & 4 & 500 & 3 \\
\hline 24 & 4 & 1 & 0 & 2 & 1 & 1 & 5 & 1 & 1 & 1 & 0 & 5 & 3500 & 3 \\
\hline
\end{tabular}

